\title{
Eduardo Peñuela, mestre de intensas
}

\section{poéticas}

\author{
Dulcilia H. Schroeder Buitoni ${ }^{1}$
}




\section{Resumo}

Palavras-chave

O artigo retoma a trajetória acadêmica de Eduardo Peñuela Cañizal desde sua formação na Faculdade de Filosofia, Letras e Ciências Humanas da USP, até sua entrada como professor na então criada Escola de Comunicações Culturais, em 1968. Por meio das aulas, orientações e pesquisas, além da publicação de inúmeros artigos e da colaboração para a criação e consolidação da pós-graduação da Escola de Comunicações e Artes da USP, vemos o caminho de um pensador, intelectual e companheiro de muitas jornadas, instaurador de um campo de pesquisa em imagens que o acompanharia até seus textos mais recentes.

Eduardo Peñuela, homenagem, memória, história.

\section{Abstract}

The present article retraces the academic trajectory of Eduardo Peñuela Cañizal, beginning with graduation from the Faculty of Philosophy, Languages and Literature, and Human Sciences (FFLCH) of the University of São Paulo (USP), Brazil, until his debut a professor at the former School of Cultural Communication, in 1968. Considering his work with classes, supervisions and researches, besides the publication of several academic articles and the collaboration with the creation and consolidation of the Postgraduate Programme of the School of Communcioation and Arts, we look at the course of an intellectual, a thinker and the colleague of many journeys. He has opened a field of study in images that he would follow to his latest writings.

\section{Keywords}

Eduardo Peñuela, tribute, remembrance, history. 
Sentados em cadeiras dentro da piscina seca, os alunos acompanhavam amores e dissabores de Artemio Cruz, revolucionário mexicano que enriqueceu e virou magnata das comunicações, no romance a três vozes de Carlos Fuentes ${ }^{2}$. A quarta voz, na borda da piscina, era de Eduardo Peñuela, que nos marcava para sempre com a visualidade de suas palavras. Era 1968 e pouco depois, na esteira de outras tomadas, os estudantes da então Escola de Comunicações Culturais da USP também ocuparam aquele barracão com a falsa piscina no meio. Em 1968, na matéria Literatura Hispano-americana, o professor espanhol com doutorado em Letras Neolatinas na FFLCH encantava os estudantes de graduação com a literatura latino-americana. Peñuela tratava de narrativas verbais que já se encenavam para nossos olhos, prenunciando a sua imersão nas poéticas visuais.

Alguns anos depois, o choque de ver um olho de mulher sendo cortado à navalha por um homem. Formigas andando numa mão masculina. Un chien andalou (Um cão andaluz) era dissecado nas aulas de pós-graduação em Ciências da Comunicação da Escola de Comunicações e Artes da USP. Aliás, Peñuela foi um dos criadores desse que seria o primeiro programa brasileiro de pós-graduação em Comunicação. Un chien andalou (1928), um dos marcos da história do cinema, causava estranhamento e atração. Filme surrealista escrito e dirigido por Luis Buñuel juntamente com Salvador Dalí; a trilha sonora era a música "Tristão e Isolda", de Wagner. Também em suas aulas assisti pela primeira vez ao O encouraçado Potemkin (Sergei Eisenstein, 1925): a cena da escada ficou para sempre na memória. Tive a felicidade de assistir a essas inquietantes e fascinantes aulas em que Peñuela mergulhava nos sonhos e na psicanálise, via análises imagéticas. Peñuela foi um dos responsáveis pelo meu percurso de pesquisa em direção às imagens, tendência que já se delineava na graduação em Jornalismo, apesar de meu amor pelo texto.

O doutorando Eduardo Peñuela lecionava na Faculdade de Filosofia, Ciências e Letras de São José do Rio Preto, interior de São Paulo. Na época, essa 
faculdade reunia importantes professores da área de Letras. Em 1964, Peñuela deixou de ser contratado devido a problemas de perseguição política. Com o início da Escola de Comunicações da USP em 1967, já doutor (1965), começou a colaborar com a matéria optativa Literatura Hispano-americana. Também sofreu obstáculos e sua matéria não foi oferecida em determinado semestre. Porém, os alunos se reuniram e combinaram com o professor um horário em que ele se ofereceu a ministrar informalmente a disciplina. Ninguém queria perder a viagem pelas paisagens latinas. Os argentinos Cortázar e seu jogo de amarelinha e sua casa tomada; Jorge Luis Borges e seus mundos imaginários; o guatemalteco Miguel Angel Asturias; os mexicanos Juan Rulfo (Pedro Páramo), Carlos Fuentes ( $A$ morte de Artemio Cruz e Aura) e Octavio Paz, poeta, ensaísta e também diplomata como Fuentes.

Carlos Fuentes nasceu em 1928, cinco anos antes de Peñuela, que é de 1933. Tinha apenas 32 anos quando narrou as transformações do seu país a partir da Revolução Mexicana, através do combatente Artemio Cruz que, rico e poderoso, está morrendo em 1959. Até hoje, está na minha memória a análise, feita por Peñuela, da cena de amor entre o soldado Artemio e a camponesa Regina.

\footnotetext{
A imaginação do rapaz saltou por cima do amor: contemplou-a adormecida como se repousasse do novo amor que em breves segundos despertá-la-ia. Quando é maior a felicidade? Acariciou o seio de Regina. Imaginar o que será uma nova união, a própria união, a alegria fatigada da lembrança e novamente o desejo pleno, aumentado pelo amor, de um novo ato de amor: felicidade. Beijou a orelha de Regina e viu de perto seu primeiro sorriso: aproximou o rosto para não perder o primeiro gesto de alegria (FUENTES, 1968, p. 59).
}

O estilo de Carlos Fuentes chama a imaginação o tempo todo; chama o visual. Utiliza ponto e vírgula e dois pontos como recursos temporais e de abertura para sequências narrativas implícitas. Peñuela também tinha muitos dois pontos em suas falas: caminhos para imagens conscientes e inconscientes.

Nos anos 1970, já na pós-graduação, Peñuela pesquisava imagens das artes plásticas, fotografias, cinema. Percorria caminhos visuais, construía teorias 
e metodologias, sempre atrás da inquietante ambiguidade da imagem. Sua atuação como docente e pesquisador aprimorou os estudos cinematográficos no Departamento de Cinema e Rádio e TV da ECA, que já era uma referência nacional e internacional em estudos sobre cinema. Suas preocupações também se estenderam aos fenômenos audiovisuais televisivos. Na década de 1980, foi presidente da Comissão de Pós-Graduação da ECA, sendo um grande criador e organizador da Pós-Graduação em Comunicação e em Artes. Embora durante vários anos a pós-graduação em cinema estivesse na área de Artes, Peñuela pensava que as duas áreas, Comunicação e Artes, deviam se interrelacionar.

Formou muitos seguidores, a todos imprimindo centelhas de pesquisa de imagem. Faço aqui uma homenagem a dois grandes discípulos, de duas gerações diferentes: Jeanne Marie Machado de Freitas, aluna da primeira turma (19671970) da ECA, e Antônio Carlos D'Ávila. Orientou o mestrado de Jeanne Marie - Os Primeiro de Maio (1979), sobre os discursos de Getúlio Vargas. Jeanne Marie teve uma carreira docente e de pesquisadora com atuações decisivas no Departamento de Jornalismo e Editoração da ECA, inclusive participando do projeto do inovador currículo de jornalismo implantado em 1992. Nos anos 1990, Jeanne Marie criou o grupo de pesquisa Ciências da Linguagem, do CNPq, junto ao Departamento de Jornalismo; esse grupo desenvolveu importantes projetos e contribuiu para a ampliação do espaço das ciências da linguagem no campo da Comunicação.

Antônio Carlos D'Ávila, de outra geração, era um jovem fotógrafo, formado em Cinema pela ECA, e depois se tornou professor do mesmo curso. Seu mestrado, Anatomia da imagem fotográfica (1987), foi um marco em termos de linguagem de dissertação. A partir de uma fotografia de uma cena interna da estação da Luz, D’Ávila montou uma argumentação inteiramente visual: recortou com estilete detalhes dessa única fotografia - reproduzida em diferentes ampliações; os recortes, organizados segundo a sequência da reflexão teórica, eram colados em pranchas. O volume da dissertação, em formato de álbum fotográfico, tinha apenas ao final umas 30 páginas de texto com discussão 
sobre imagem. Trinta páginas densas e poéticas. Participei da banca de defesa desse trabalho de Antônio Carlos D'Ávila - um momento de grande criatividade científica e acadêmica. Peñuela orientou seu doutorado, Diário de um fotógrafo viajante (1995), uma tese também inovadora. Antônio Carlos D’Ávila participou de projetos importantes, como a documentação da viagem de Paulo Vanzolini pelo rio Amazonas e a expedição pela Antártida com o navio professor W. Besnard, da USP. Foi diretor de fotografia, entre outros, dos filmes documentários de Ricardo Dias: No rio das amazonas (1995) e Fé (lançado em 1999). Jeanne Marie faleceu em 2009 como professora titular da ECA; D'Ávila era um jovem professor doutor e faleceu em 1998.

Eduardo Peñuela sempre manteve relações acadêmicas internacionais. Além de dois pós-doutorados nos Estados Unidos, um deles em Stanford, mantinha contato com pesquisadores latino-americanos e principalmente pesquisadores da Universidad Autònoma de Barcelona, onde seu grande interlocutor era o professor José Manuel Perez Tornero. Peñuela iniciou os contatos que culminaram com a assinatura do convênio ECA/Universidad Autònoma de Barcelona (UAB) em 1991, já na gestão do professor José Marques de Melo como diretor da ECA. Esse convênio fazia o intercâmbio de professores das faculdades de Comunicação de USP e da UAB que eram selecionados para ministrar cursos de pós-graduação. Anualmente, vinham dois professores da UAB em setembro e dois professores da USP iam em fevereiro.

Peñuela sucedeu José Marques de Melo na diretoria da ECA, dando grande impulso à pós-graduação, da qual já tinha sido coordenador anteriormente. Não preciso lembrar sua atuação mais tarde, quando por três vezes foi representante da área da Comunicação junto à Capes em Brasília, colaborando para a maturidade dos estudos de Comunicação em nível de pós-graduação e para a articulação dos programas das diferentes regiões. Quero lembrar mais o professor que produzia emoções acadêmicas e estéticas, e também o examinador dedicado, que participou de bancas comigo e que até o fim da vida se dispunha a participar de bancas no interior, como uma de livre-docência em Bauru, quando 
fomos todos num antigo carro oficial da Unesp. Peñuela também foi membro da banca onde obtive o título de professora titular em Jornalismo, em 1991. Uma das lembranças mais queridas era quando, como chefe de departamento, ia conversar com o diretor Eduardo Peñuela. Ao chegar à sala, ele quase sempre estava sentado numa outra mesa lateral, lendo alguma revista científica; usava qualquer tempo disponível para a sua paixão pelo conhecimento.

O intelectual inquieto estava em constante elaboração de artigos, aulas, palestras, sempre em busca de conceitos que mexiam com a cabeça de seus leitores. Um de seus últimos textos, o artigo Enquadramentos ideológicos e escriturais em textos visuais, publicado na revista MATRIZes (julho-dezembro de 2013) ${ }^{3}$, começa com uma epígrafe de Gaston Bachelard, um dos meus autores preferidos (e muito combatido nas décadas de 1960 e 1970, quando comecei a usá-lo em pesquisas), que diz: "O desejo de olhar para dentro das coisas faz com que a vista se torne aguçada, o olhar se torne penetrante". Peñuela tinha a vista aguçada e o olhar penetrante. Nesse artigo, trabalha com o conceito de paisagem, com o intuito de analisar efeitos comunicativos e poéticos presentes em textos visuais. De Bachelard ele vai para obras de pintura, para fotografias, passa por filmes clássicos e termina com o documentário Cave of the forgotten dreams (2011), de Werner Herzog. Das cavernas da Andaluzia, onde parece que ele se escondeu quando menino, durante a Guerra Civil Espanhola, ele vai para a caverna ancestral:

Por meio do prisma da imaginação, os arranjos feitos por Herzog para filmar as cenas e ajustar o preâmbulo de uma exibição em comum criaram a pregnância inevitável para entrever em tudo isso a metáfora de uma topografia do inconsciente ou de um lugar propício para o devaneio inquieto que envolve a mente de um espectador quando ele percebe a escuridão de uma sala de cinema atravessada, de repente, pelo feixe de luz que vem do projetor (PEÑUELA CAÑIZAL, 2013, p. 108). 
A paisagem, nesses textos figurativos da arte rupestre, não está explicitamente presente. Peñuela intui a presença do inconsciente:

Isso me faz refletir sobre o fato de que as imagens rupestres guardam na materialidade de seus suportes rochosos uma sutil lembrança paisagística, pois é muito difícil olhar para estes rochedos parietais sem que me venha à memória, vagamente, o esboço intuitivo de um lugar geológico escondido nas regiões mais misteriosas do inconsciente (PEÑUELA CAÑIZAL, 2013, p. 109).

Eduardo, leitor poético, leitor visualmente poético, deixou seus rastros de sentimento e emoção. Deixou muitas pistas de sua paisagem interior. Por isso, ele está em nossa memória.

Se Artemio Cruz termina com a frase: "(...) Tu... morres... morreste... morrerei", para Peñuela, dizemos: "(...) Tu... vives... viveste... viverás". 


\section{Referências}

PEÑUELA CAÑIZAL, Eduardo. Enquadramentos ideológicos e escriturais em textos visuais. Revista MATRIZes, no 2, jul/dez de 2013. São Paulo, Brasil. p. 95-111.

FUENTES, Carlos. A morte de Artemio Cruz. Rio de Janeiro: Edinova, 1968. 